\title{
Obstetric emergency preparedness among staff nurses working in obstetric care units
}

\author{
Namitha Subrahmanyam*, Jisha Joseph, Rinu Abraham
}

Department of Obstetrical and Gynaecological Nursing, Malankara Orthdox Syrian Church College of Nursing, Kolenchery, Ernakulam, Kerala, India

Received: 21 April 2017

Accepted: 18 May 2017

\section{*Correspondence:}

Dr. Namitha Subrahmanyam,

E-mail: namithanijeesh@gmail.com

Copyright: (C) the author(s), publisher and licensee Medip Academy. This is an open-access article distributed under the terms of the Creative Commons Attribution Non-Commercial License, which permits unrestricted non-commercial use, distribution, and reproduction in any medium, provided the original work is properly cited.

\section{ABSTRACT}

Background: Pregnancy and child birth process heralds some risks at every point of time. Being primary health care provider nurses have key roles in identification and prompt management of obstetric emergencies. The aim of this study was to assess the obstetric emergency preparedness among staff nurses working in obstetric care units of a tertiary care centre.

Methods: A descriptive survey was carried out among all staff nurses $(n=117)$ working in obstetric care units of a tertiary care hospital in Ernakulam district, Kerala using a structured questionnaire that contain items on personal and professional characteristics and obstetric emergency preparedness.

Results: The percentage of nurses reported attendance to obstetric emergency drills at work setting (28.2\%), Familiarity with procedures for staff call up systems during emergencies (44.4\%), Familiarity with emergency crash cart at work setting (50.4\%) and being acquainted with correct triaging of obstetric emergencies $(57.3 \%)$ were found to be low in the study. The overall emergency preparedness score showed significant association with age $(\mathrm{p}=0.003)$, educational qualification $(\mathrm{p}=0.002)$, type of employment $(\mathrm{p}=0.001)$, years of experience $(\mathrm{p}=0.016)$, experience in handling obstetric emergencies $(\mathrm{p}=0.015)$ and attendance to Continuing Nursing Education(CNE) on obstetric emergencies $(\mathrm{p}=0.001)$.

Conclusions: The areas where the nurses lag obstetric emergency preparedness need to be strengthened through appropriate empowerment strategies in order to ensure competency in managing obstetric emergencies among staff nurses.

Keywords: Obstetric emergency preparedness, Staff nurses

\section{INTRODUCTION}

There are certain categories of pregnancies (20-30\%) where the mother, the fetus, or neonate is in a state of increased jeopardy. This group must be identified and given extra care to improve obstetric result as this group is responsible for $70-80 \%$ of perinatal mortality and morbidity. ${ }^{1}$ The maternal mortality ratio (MMR), expressed as maternal deaths per 100,000 live births over a given period, is a major measure of quality of obstetric care. According to World Health Organization (WHO) estimates, it varies up to 100 -fold, from approximately 10 in developed countries to approximately 1,000 in least developed. $^{2}$ Obstetric complications can neither be predicted nor be prevented but can be managed by timely provision of life saving services. Maternal death is usually the end result of inadequately or inappropriately managed complications arising during pregnancy and child birth. ${ }^{3}$ Quality of care in Emergency obstetrics involves institutional and staff preparedness in the provision of appropriate emergency services while responding to the needs and rights of the clients. These 
include having staff with relevant skills available, having functional equipment and supplies, and having adequate infrastructure, all of which are prerequisites for the provision of prompt and appropriate care when emergencies arise. Proper knowledge about identification signs, emergency measures to be taken and well equipped obstetric unit can reduce maternal mortality by almost 35$40 \% .^{4}$ As the nurses being the primary health care providers, their preparedness for obstetric emergencies attains paramount importance. The challenges perceived by them in managing those urgent situations demand immediate interventions in order to ensure safe pregnancy and child birth for obstetric population.

\section{METHODS}

This was a cross sectional descriptive study conducted in the Department of Obstetrics and Gynecology of a tertiary care hospital in the state of Kerala, India in the year 2016. The study was approved by the institutional ethics committee. All nurses providing obstetric care to the women in labour, antenatal and post-natal period were offered voluntary participation in the study after explaining about the items of questionnaire in detail. After obtaining informed consent, 117 staff nurses were enrolled in the study using total enumerative sampling. Data were collected using a structured questionnaire that contain items on personal and professional characteristics and obstetric emergency preparedness.

\section{RESULTS}

The data were analysed using statistical package SPSS version 20. The Mean age of participants was 30.79 \pm 5.13 (Range 22-51) and majority were females (99.1\%). Regarding the educational qualification, $80.3 \%$ reported to have Diploma in GNM and a greater portion of the subjects $(89.7 \%)$ were permanent employees.

Table 1: Frequency distribution and percentage of subjects based on personal characteristics $n=117$.

\begin{tabular}{|llll|}
\hline $\begin{array}{l}\text { Socio personal } \\
\text { characteristics }\end{array}$ & Mean \pm SD & Range \\
\hline \multirow{2}{*}{ Age in years } & & $30.79 \pm 5.13$ & $22-51$ \\
\cline { 2 - 4 } Gender & Male & 1 & $(\%)$ \\
\hline & Female & 116 & 0.9 \\
\hline \multirow{2}{*}{ Education } & $\begin{array}{l}\text { General } \\
\text { Nursing and }\end{array}$ & 94 & 99.1 \\
\hline & $\begin{array}{l}\text { Midwifery } \\
\text { B Sc Nursing }\end{array}$ & 10 & 80.3 \\
\cline { 2 - 4 } & $\begin{array}{l}\text { Post Basic } \\
\text { Type of }\end{array}$ & BSc Nursing \\
Employment & Permanent & 13 & 8.5 \\
\cline { 2 - 4 } & Contract & 12 & 11.1 \\
\hline
\end{tabular}

Majority $(83.9 \%)$ of the nurses had $>3$ years of working experience and $71.79 \%$ had more than three years of working experience in Obstetric unit. Nearly two-third $(63.2 \%)$ reported to have experience in handling obstetric emergencies. Majority (68.4\%) stated attendance to CNE on obstetric emergencies.

Table 2: Frequency distribution and percentage of subjects based on professional characteristics $n=11$.

\begin{tabular}{|llll|}
\hline \multirow{3}{*}{$\begin{array}{l}\text { Professional characteristics } \\
\text { Years of total Experience }\end{array}$} & (f) & $(\%)$ \\
\cline { 2 - 4 } & < one year & 12 & 10.20 \\
\cline { 2 - 4 } & 1-3 years & 8 & 6.90 \\
\cline { 2 - 4 } & > 3years & 97 & 83.90 \\
\hline \multirow{2}{*}{$\begin{array}{l}\text { Experience in obstetric } \\
\text { unit }\end{array}$} & < one year & 14 & 11.98 \\
\cline { 2 - 4 } & 1-3 years & 19 & 16.23 \\
\cline { 2 - 4 } $\begin{array}{l}\text { Experience in handling } \\
\text { obstetric emergencies }\end{array}$ & Yes years & 84 & 71.79 \\
\hline $\begin{array}{l}\text { Attendance to CNE on } \\
\text { obstetric emergencies }\end{array}$ & No & 74 & 63.2 \\
\hline
\end{tabular}

\section{Obstetric emergency preparedness among staff nurses}

Surprisingly greater portion of the participants reported emergency preparedness in terms of having established protocols for management of obstetric emergencies at work setting (82.9\%), awareness about specific roles and responsibilities during emergencies (81.2), Skill in using personnel protective equipment's (82.9\%) and competency in prompt identification and proper notification of the occurrence of an emergency event $(83.6 \%)$.

Table 3: Frequency distribution and percentage of subjects based on obstetric emergency preparedness $\mathrm{n}=\mathbf{1 1 7}$.

\begin{tabular}{|l|cc|}
\hline $\begin{array}{l}\text { Selected areas of Obstetric emergency } \\
\text { management preparedness }\end{array}$ & f \\
\hline $\begin{array}{l}\text { Have competency in prompt identification } \\
\text { and notification of the occurrence of an } \\
\text { emergency event }\end{array}$ & 87 & 74.4 \\
\hline $\begin{array}{l}\text { Have established protocols for } \\
\text { management of obstetric emergencies at } \\
\text { work setting }\end{array}$ & 96 & 82.9 \\
\hline $\begin{array}{l}\text { Awareness about specific roles and } \\
\text { responsibilities during emergencies }\end{array}$ & 95 & 81.2 \\
\hline $\begin{array}{l}\text { Acquainted with correct triaging of } \\
\text { obstetric emergencies }\end{array}$ & 67 & 57.3 \\
\hline $\begin{array}{l}\text { Skill in using personnel protective } \\
\text { equipments }\end{array}$ & 96 & 82.9 \\
\hline $\begin{array}{l}\text { Familiarity with procedures for staff call } \\
\text { up systems during emergencies }\end{array}$ & 52 & 44.4 \\
\hline $\begin{array}{l}\text { Attendance to obstetric emergency drills } \\
\text { at work setting }\end{array}$ & 33 & 28.2 \\
\hline $\begin{array}{l}\text { Familiarity with emergency crash cart at } \\
\text { work setting }\end{array}$ & 59 & 50.4 \\
\hline
\end{tabular}

However, the percentage of nurses reported attendance to obstetric emergency drills at work setting (28.2\%), 
Familiarity with procedures for staff call up systems during emergencies (44.4\%), Familiarity with emergency crash cart at work setting $(50.4 \%)$ and being acquainted with correct triaging of obstetric emergencies $(57.3 \%)$ were found comparatively low.

The overall obstetric emergency preparedness score showed significant association with age $(\mathrm{p}=0.003)$, educational qualification $(\mathrm{p}=0.002)$, type of employment $(\mathrm{p}=0.001)$, years of experience $(\mathrm{p}=0.016)$, experience in handling obstetric emergencies $(\mathrm{p}=0.015)$ and attendance to CNE on obstetric emergencies $(\mathrm{p}=0.001)$.

Table 4: Association of overall obstetric emergency preparedness score with selected variables of subjects $\mathrm{n}=117$.

\begin{tabular}{|llll|}
\hline $\begin{array}{l}\text { Personal and professional } \\
\text { variables }\end{array}$ & $\chi^{2}$ & df & $\begin{array}{l}\text { p } \\
\text { value }\end{array}$ \\
\hline Age & 08.80 & 1 & $0.003^{*}$ \\
\hline Educational qualification & 12.27 & 2 & $0.002^{*}$ \\
\hline Type of employment & 11.07 & 1 & $0.001^{*}$ \\
\hline $\begin{array}{l}\text { Years of experience } \\
\text { Experience in handling obstetric } \\
\text { emergencies }\end{array}$ & 05.95 & 1 & $0.015^{*}$ \\
\hline $\begin{array}{l}\text { Attendance to CNE on obstetric } \\
\text { emergency management }\end{array}$ & 10.51 & 1 & $0.001^{*}$ \\
\hline $\begin{array}{l}\text { Level of significance p<0.05* } \\
\text { Level of significance } p<0.05^{*}\end{array}$ & & & $0.016^{*}$ \\
\hline
\end{tabular}

\section{DISCUSSION}

Improvement of maternal and neonatal health is associated with increased access to high-quality emergency obstetric and neonatal care (EmONC) services. ${ }^{5}$ Health worker preparedness to provide EmOC is the most critical element in the provision of quality care, in that they must have the knowledge and skills to recognize an obstetric emergency and then respond appropriately. ${ }^{6}$

Triage decisions are fundamental in determining the trajectory of emergency care, and the accuracy of triage decisions is a major influence on patient out-comes. ${ }^{7}$ In the present study more than a quarter of subjects $(25.6 \%)$ reported that they are not competent in prompt identification and proper notification of the occurrence of an emergency event. A greater portion (57.3\%) of the participants were not acquainted with correct triaging of obstetric emergencies. Similar to this finding, many studies have shown that nurses have inadequate knowledge and skill in emergency triaging., 8 A recent confidential enquiry published in 2007 recommended that all clinical staff undertake regular, written, documented, and audited training for the early recognition and management of severely ill pregnant women with impending collapse. $^{10}$ In the context of obstetric emergencies, employing experienced and skilled nurses for the triaging emergencies, and teaching them how to properly perform triage can prevent death, disabilities, and additional costs of treatment both for the woman and the neonate is utmost important. Frequent in-service training may be imparted on this topic to nurses working in obstetric care units to improve maternal and neonatal outcome. Majority of the subjects reported to have established protocols for management of obstetric emergencies at work setting $(82.9 \%)$. Standardized evidence based protocols reduces the incidents of clinical errors in emergency situations.

As per the findings of the study, the percentage of nurses reported attendance to obstetric emergency drills at work setting $(28.2 \%)$, familiarity with emergency crash cart at work setting (50.4\%) were low. Saissakos, et al. (2009), found obstetric units that used simulation for drills had better clinical outcomes and the staff that received this training sustained improvements in their knowledge and confidence levels where obstetric emergencies were concerned. ${ }^{11}$ Appropriately trained personnel and the provision of necessary supplies and equipment are critical to the development and implementation of EmOC services. ${ }^{12}$ Hence nurses working in obstetric units must be provided with opportunity to attend training sessions on obstetric emergencies.

Even though the awareness about specific roles and responsibilities during emergencies was found higher $(81.2 \%)$, familiarity with procedures for staff call up systems during emergencies $(44.4 \%)$ was low among the subjects. Enquiries into suboptimal outcomes have identified common errors: confusion in roles and responsibilities, lack of cross-monitoring, failure to prioritise and perform clinical tasks in a structured coordinated manner, poor communication and lack of organizational support. ${ }^{13,14}$ As a consequence, there has been a shift away from individual responsibility towards improved team working. In order to accomplish an effective team work, each one working in the emergency situation needs to get acquainted with staff call up systems of the organization and must be designated with clear roles and responsibilities. The core elements of emergency obstetric care include availability of essential drugs and supplies, patient referrals and the availability of skilled personnel to carry out effective interventions. Skilled health professionals working in favourable environment should be available and able to attend to every pregnancy and delivery. ${ }^{15}$

In this study, the overall obstetric emergency preparedness score showed significant association with age $(p=0.003)$, educational qualification $(p=0.002)$, type of employment $(\mathrm{p}=0.001)$, years of experience $(\mathrm{p}=0.016)$, experience in handling obstetric emergencies $(\mathrm{p}=0.015)$ and attendance to $\mathrm{CNE}$ on obstetric emergencies $(\mathrm{p}=0.001)$. This supports with a finding by Usher et al that advanced age, disaster education and training and previous disaster involvement was a predictor for increased disaster competence and preparedness in nurses. ${ }^{16}$ In a study conducted by Baack S, et al authors revealed that the nurses who were confident were more 
likely to have had actual prior experience in disasters or shelters. ${ }^{17}$ Similarly, the more years a health provider provided delivery services, the more likely he or she was able to name appropriate actions for handling clients with complications of retained placenta and haemorrhage. ${ }^{18}$ The findings suggest further enquiries in order to identify the factors determining nurses' obstetric emergency preparedness.

\section{CONCLUSION}

Nurses play a significant role in the identification and management of obstetric emergencies. Therefore, they need to be prepared to respond promptly and effectively so that negative consequences arising out of these events can be better handled. The areas in which they possess minimal preparedness should be identified and dealt seriously to safeguard the life of pregnant woman and the hidden client- the fetus presenting in obstetric emergencies.

\section{ACKNOWLEDGMENTS}

Authors would like to thank all nurses who participated in the study.

\section{Funding: No funding sources}

Conflict of interest: None declared

Ethical approval: The study was approved by the Institutional Ethics Committee

\section{REFERENCES}

1. Onakewhor JU, Gharoro EP. Changing trends in maternal mortality in a developing country. Nigerian J ClinicPract. 2008;11(2):111-20.

2. Hill K, AbouZahr C, Wardlaw T. Estimates of maternal mortality for 1995. Bullet World Health Organizat. 200179(3):182-93.

3. Verma S, Jain M, Budhwani C. Obstetric emergencies: preparedness among nurses for safe motherhood. Internat J Reproduct Contracept Obstetr Gynecol. 2016;5(4):998-1001.

4. Park K. Health programs in India. In Park's text book of preventive and Social Medicine, 20th edn, Bhanot publishers, Jabalpur, India; 2009:359-92.

5. Chowdhury ME, Botlero R, Koblinsky M, Saha SK, Dieltiens G, Ronsmans C. Determinants of reduction in maternal mortality in Matlab, Bangladesh: a 30year cohort study. The Lancet. 2007;370(9595):1320-8.

6. National Coordinating Agency for Population and Development (NCAPD) [Kenya], Ministry of Health $(\mathrm{MOH})$, Central Bureau of Statistics (CBS), ORC Macro. 2005. Kenya.

7. Gerdtz MF, Bucknall TK. Why we do the things we do: applying clinical decision-making frameworks to triage practice. Accident and Emergency Nursing. 1999;7(1):50-7.

8. Fry M, Burr G. Current triage practice and influences affecting clinical decision-making in emergency departments in NSW, Australia. Accident and emergency nursing. 2001;9(4):227-34.

9. Rahmati H, Azmoon M, Meibodi MK, Zare N. Effects of Triage Education on Knowledge, Practice and Qualitative Index of Emergency Room Staff: A Quasi-Interventional Study. Bullet emergenc traum. 2013;1(2):69.

10. CEMACH. Saving Mothers' Lives 2003-2005. The Seventh Report of the Confidential Enquires into Maternal Deaths in the United Kingdom. London: RCOG Press; 2007.

11. Siassakos D, Crofts JF, Winter C, Weiner CP, Draycott TJ. The active components of effective training in obstetric emergencies. BJOG: An Internat J Obstetr Gynaecol. 2009;116(8):1028-32.

12. Mavalankar DV, Rosenfield A. Maternal mortality in resource-poor settings: policy barriers to care. Americ J Public Health. 2005;95(2):200-3.

13. Siassakos D, Timmons C, Hogg F, Epee M, Marshall L, Draycott T. Evaluation of a strategy to improve undergraduate experience in obstetrics and gynaecology. Medical education. 2009;43(7):669-73.

14. Bowyer L. The Confidential Enquiry into Maternal and Child Health (CEMACH). Saving Mothers' Lives: reviewing maternal deaths to make motherhood safer 2003-2005. The Seventh Report of the Confidential Enquiries into Maternal Deaths in the UK. Obstetric Medicine. 2008;1(1):54.

15. World Health Organization, UNICEF. Reduction of maternal mortality: a joint WHO/UNFPA/UNICEF/World Bank statement. World Health Organization; 1999.

16. Usher K, Mills J, West C, Casella E, Dorji P, Guo A, et al. Cross-sectional survey of the disaster preparedness of nurses across the Asia-Pacific region. Nurs Health Sci. 2015;17(4):434-43.

17. Baack S, Alfred D. Nurses' preparedness and perceived competence in managing disasters. Journal of Nursing Scholarship. 2013;45(3):281-7.

18. Olenja, Joyce, Pamela Godia, Josephine Kibaru, and Thaddaeus Egondi. Influence of Provider Training on Quality of Emergency Obstetric Care in Kenya. Kenya Working Papers No.3. Calverton, Maryland, USA: Macro International Inc; 2009.

Cite this article as: Subrahmanyam N, Joseph J, Abraham R.Obstetric Emergency Preparedness among staff nurses working in obstetric care units. Int J Reprod Contracept Obstet Gynecol 2017;6:2960-3. 